\title{
O CONVITE À VIAGEM: \\ NOTAS SOBRE O EXÓTICO NAS FLORES DO MAL
}

\author{
INVITATION TO THE VOYAGE: \\ NOTES ON THE EXOTICISM IN LES FLEURS DU MAL
}

Paulo FRANCHETTI ${ }^{7}$

RESUMO: Por meio da consideração dos principais poemas que tratam de ambientes ou tempos exóticos, busca-se aqui refletir sobre as edições das Flores do Mal, do ponto de vista da sua organização sequencial e temática.

PALAVRAS-CHAVE: Exotismo; Baudelaire; Poesia moderna.

ABSTRACT: This paper focuses on the representation of exotic places in the poems of the first edition of Les Fleurs du Mal, aiming to discuss the organization of the book before censorship's intervention.

KEYWORDS: Exoticism; Baudelaire; Modern poetry.

A primeira edição das Flores do Mal, datada de 1857, era composta por 101 poemas.

100 deles eram numerados. O primeiro vinha separado do conjunto principal, sem número, e era denominado "Ao leitor" ". Já os 100 poemas numerados distribuíam-se por 5 partes.

7 Departamento de Teoria Literária, Instituto de Estudos da Linguagem, Universidade Estadual de Campinas (UNICAMP), CEP 13083-970, Campinas, SP, paulo@iel.unicamp.br

8 Para maior comodidade e fluidez da leitura, refiro os poemas pelos títulos traduzidos, conforme Charles Baudelaire. Poesia e prosa. Edição organizada por Ivo Barroso. Rio de Janeiro: Editora Nova Aguilar, 1995, dispondo em nota de rodapé o título original. Neste caso: Au lecteur 
A primeira, denominada "Spleen e ideal" continha 77; a segunda, que levava o mesmo título do livro, 1210; a terceira seção, "Revolta" ${ }^{11}$, trazia 3 poemas; a quarta, intitulada "O vinho" ${ }^{12}$, continha 5; e a última, denominada "A morte" ${ }^{13}$, era composta por 3 peças.

O número redondo dos poemas numerados, a presença de um prólogo em versos, bem como a divisão clara das partes sob nomes fortes, terminando pela morte, demandam um percurso de leitura, estimulam o leitor a perseguir o que, segundo Barbey d'Aurevilly seria a "arquitetura secreta", o "plano calculado pelo poeta, meditativo e voluntário" de um livro que seria menos uma coletânea de "poesias do que uma obra poética da mais forte unidade", que demandava leitura na ordem em que os poemas aparecem no seu interior, sem o que muito perderia o livro, inclusive "do ponto de vista do efeito moral". ${ }^{14}$

Quando a obra é condenada pela censura, que exige a retirada de 6 poemas, Baudelaire recorre afirmando o "perfeito conjunto", que desde logo ficaria comprometido pela supressão dos poemas censurados. Assim também na carta à imperatriz, de 6 de novembro de 1857, afirma que tinha sido condenado a "refazer o livro" - ou seja, a retirada dos 6 poemas não lhe parecia possível sem que o desenho todo do volume fosse refeito, alterado. ${ }^{15}$

9 Spleen et idéal

10 Fleurs du Mal

11 Révolte

12 Le vin

13 La mort

14 Cf. "Les fleurs du mal par M. Charles Baudelaire”. Repr. em Baudelaire, Charles. Oeuvres complètes. Texte établi, presente et annoté par Claude Pichois. Paris, Gallimard, 1975. As notas e variantes das Flores do Mal, nesse volume são de autoria de Jean Ziegler. É certo que sempre se pode argumentar, como Ziegler, que o artigo de Aurevilly não era inocente, no sentido que teria sido escrito para facilitar a defesa de Baudelaire perante a censura, conforme a carta que o acompanha: "l'article que vous m'avez demandé". 
E de fato é o que faz, na segunda edição, de 1861: retira os poemas condenados e acrescenta 35 outros. Tal inclusão (o acrescentamento foi da ordem de 1/3 do número anterior) se acompanha não apenas da criação de uma nova seção ("Quadros Parisienses" ${ }^{16}$ ), mas ainda da alteração na ordem das que existiam em 1857 - agora, "O vinho" - que antes estava entre "Revolta" e "A morte" - recua para antes de "Flores do Mal", vindo logo após os "Quadros Parisienses".

A nova seção - que, a partir de Benjamin, concentraria boa parte da atenção crítica, como se fosse a epítome do livro - se organiza, por sua vez, por meio do remanejamento de 8 poemas anteriormente integrados a "Spleen e ideal" e do acréscimo de 10 outros, que estavam ausentes da edição de 1857.

Muito haveria que comentar sobre as diferenças entre ambas as edições, se este fosse o objetivo desta comunicação. Não sendo, queria apenas registrar uma das principais intervenções na seção "Spleen e ideal": a substituição do poema "O sol” os "Quadros Parisienses" - pelo soneto "O Albatroz" ${ }^{18}$. Aqui está um dos sentidos da reformulação do livro: após a intervenção da censura, o lugar anunciado para o poeta deixa de ser o do sol, que ilumina igualmente as coisas belas e as imundas, e passa a ser o da ave hostilizada e metida em ridículo, quando em terra. Em ambos, o símile mostra que o lugar do poeta são as alturas. Mas enquanto na primeira edição a ênfase estava no brilho e na altaneria, na segunda o que vem para primeiro plano é a humilhação e a vingança do inferior.

Por fim, queria observar que, até 1966, todas as edições disponíveis parecem ter se originado da edição de 1861. Algumas tentando reintroduzir nela os seis poemas condenados, outras deixando-os fora do corpo do livro.

15 Reproduzida em Baudelaire, Charles. Les fleurs du mal. Édition établie selon un ordre nouveau, présentée et annotée para Yves Florenne. Paris : Le Livre de Poche, 1972, p. 324.

16 Tableaux parisiens

17 Le soleil

18 L'albatros 
Pessoalmente, prefiro ler as Flores do Mal na ordem da edição - muito criticada, do ponto de vista filológico, mas inovadora - que Yves Florenne publicou em 1966: primeiro As Flores do Mal, tal como publicadas antes da censura; e, em seguida, os conjuntos acrescentados nas edições posteriores.

Nesta comunicação, por meio da leitura do motivo exótico nas Flores do Mal, o que vou tentar fazer é uma demonstração, no que diz respeito aos poemas em que esse tema tem lugar central, da cerrada estrutura do livro de 1857.

\section{II}

Do ponto de vista da cronologia, a evolução do tema do lugar exótico se desdobra entre 1841 e 1855: o primeiro momento está representado por "A uma dama creoula", ${ }^{19} \mathrm{e} o$ segundo pelo núcleo de poemas compostos em 1855, entre os quais se inclui "Moesta et errabunda" e "O convite à viagem" 20 .

Em ambas as edições de As Flores do Mal, "A uma dama creoula" vem imediatamente antes de "Moesta et errabunda". Mas apenas na de 1857 estão esses dois poemas colocados imediatamente antes de "Os gatos" ${ }^{21} \mathrm{e}$ "Os mochos" ${ }^{22}$, compondo com eles um conjunto que dá conta não apenas da evolução e resolução da temática exotista nas Flores do Mal, mas ainda do fracasso da evasão exótica, com a confissão da impotência do apelo à viagem para combater o spleen vitorioso.

De fato, "Os gatos" e "Os mochos" são elogios à vida sedentária, impassível. Este último termina, inclusive, por um terceto irônico: "o homem ... carrega sempre o castigo de

19 À une dame créole

20 L'invitation au voyage

21 Les chats

22 Les Hiboux 
ter pretendido mudar de lugar" - no qual ecoam lugubremente os versos de "Moesta et errabunda". E, no fecho desse desenvolvimento, a "Os mochos" se segue " sino rachado" ${ }^{23}$, no qual a imobilidade fornece um dos símiles mais fortes da angústia, quando a alma do poeta é comparada a um soldado ferido que agoniza, sem poder fazer qualquer movimento, sob um grande monte de companheiros mortos.

Vejamos agora a estrutura do livro [de 1857], no que diz respeito ao tratamento do exótico. A primeira constatação da leitura sequencial é que o espaço exótico, isto é, o espaço do outro, o espaço-outro, aparece nas Flores do Mal sob duas rubricas: o jadis e o làbas. Num, temos o sonho exotista que se faz por meio do deslocamento no tempo; noutro, por meio do deslocamento no espaço. Um é o domínio da reminiscência ou da reconstrução “arqueológica”. Outro, o da viagem. Em ambos os casos, temos mundos que se contrapõem com vantagem àquele a que o poeta está confinado.

Na sequência das Flores do Mal (1857), a primeira aparição do exótico se dá em estreita associação com o tema platônico do mundo superior, tal como descrito no Fédon. De fato, logo depois da apresentação do poeta e de uma alegoria sobre a sua missão no mundo (“O sol”24), o terceiro poema do livro, "Elevação" ${ }_{25}$, põe subitamente em cena o tema da terra degradada em que habitamos, a que se opõem as regiões puras a que o espírito se pode elevar. A forma de aceder a esse lugar de unidade é o exercício das "Correspondências" 26 (poema IV), que, na sequência do livro, surge como a forma de recuperar a "obscura e profunda unidade" do mundo a partir da "analogia recíproca" entre os dados dos sentidos. ${ }^{27}$

23 La cloche fêlée

24 Le soleil

25 Élévation

26 Correspondances

27 « Richard Wagner e Tannhäuser em Paris ». Baudelaire. Poesia e Prosa, cit., p. 917. 
É nesse momento, anunciado o propósito de recuperar a unidade, que surge o primeiro poema exotista das Flores do Mal, o que começa "Amo a recordação..." (V) ${ }^{28}$, em que se evoca um mundo paradisíaco explicitamente contraposto aos horrores do mundo moderno, concretizados na deformidade dos corpos contemporâneos moldados pela imbecilidade, pelo erro, pelo pecado e pela mesquinhez.

$\mathrm{O}$ mundo anterior ao pecado, idealizado nessas épocas nuas, é o mundo em que a carne é magnífica e o homem reina pela beleza física - o mundo pagão, a que o espírito, transcendendo os limites do presente, consegue erguer-se em contemplação.

Logo no início do livro, o exótico comparece, então, sob a forma do deslocamento temporal, como tentativa de remontar, pela evocação e pelo exercício das correspondências, à Idade de Ouro, na qual o homem teria conhecido a plenitude física e sensória - agora perdida.

Não temos, porém, aqui, uma solução pacífica, mas sim uma tensão ambígua. Por um lado, trata-se de um desejo e uma proposta de elevação espiritual: na medida em que o poeta se valeria dos sentidos para recompor a unidade básica do mundo, os dados sensuais deixariam de importar em si mesmos, passariam a valer como índices de algo que os transcende e que lhes dá significado. Por outro lado, fica patente já neste quinto poema do livro que o ideal é a fruição da sensualidade em um espaço outro, que permita a suspensão da culpa e do remorso - ou seja, que o sensual é objetivo em si, pois, como os frutos, a carne do homem da idade de ouro não só é saudável e elástica, mas também convida à mordida erótica.

Veem-se bem, portanto, os suportes desse exotismo: o horror ao ambiente mesquinho que cerceia o poeta e o desejo de livre exercício dos sentidos e dos instintos.

Essa tensão entre o que o poeta denominou em outro texto o esforço de subir e a alegria de descer se cristaliza nos seis poemas seguintes, que têm marcada unidade temática, e tratam das artes (do ideal artístico e luciferino em seu desejo de totalidade [“Os faróis” ${ }^{29}$ ),

28 J'aime le souvenir de ces époques nues

29 Les phares 
e dos obstáculos à concretização desse ideal. ${ }^{30}$ Em outras palavras, nos termos baudelairianos, tratam da busca da unidade básica do mundo por meio da análise das correspondências e dos obstáculos que se apresentam ao indivíduo concreto que se dedica a esse objetivo: a doença, a venalidade, a preguiça, a velhice e o acaso [“A musa doente", "A musa venal", "O mau monge", "O inimigo" e "O azar"

E então, como que emoldurando esse núcleo coeso, eis que vem o poema "A vida anterior" [XII], ${ }^{32}$ assinalando os limites do exotismo do jadis, pois aí o passado reconstruído pela imaginação ou pela reminiscência não é a plenitude da aurea aetas, mas um tempo espelho do presente, em que se equilibram a volúpia e a melancolia, sob a qual perpassa, numa mise-en-abîme, outra e saudosa lembrança de um tempo ainda anterior.

Na sequência dessa espécie de confissão do malogro do exotismo temporal, surge o tema da viagem, do deslocamento espacial, com os poemas "Ciganos em viagem" [XIII] ${ }^{33} \mathrm{e}$ “O homem e o mar" [XIV] ${ }^{34}$. Em ambos, não são os limites temporais, mas os físicos, que aparecem como obstáculos a vencer para a conquista da liberdade e do futuro. Ambos referem a ação de forçar os limites espaciais como uma ação repetida desde o começo dos tempos. Em "O homem e o mar", explicitamente. Em "Ciganos em viagem”, de modo implícito, porque só percebemos que sob a roupagem antiga dos comediantes se figura o homem da idade de ouro quando novamente comparece Cibele, cuidando maternalmente deles com a mesma solicitude com que alimentara o homem e a mulher perfeitos do poema número $\mathrm{V}$.

30 Na edição da Aguilar, há uma inversão na ordem, vindo “Os faróis” antes de "Amo a recordação...”.

31 La muse malade; La muse vénale; Le mauvais moine; L'ennemi

32 La vie antérieure

33 Bohémiens en voyage

34 L'homme et la mer 
No entanto, há poucos poemas em que a viagem, o deslocamento espacial surge como realidade. Nos mais importantes, trata-se de uma viagem mental, de transporte imaginário ou de vaga possibilidade de deslocamento. Em "Perfume exótico" $[\mathrm{XXI}]^{35}$, o primeiro a nomear a natureza exótica, o que temos é a construção de uma paisagem a partir de um dado sensual concreto: o odor do corpo da mulher amada. Trata-se, ainda, portanto, de exercício de descoberta da analogia entre os dados dos sentidos. Mas aqui não mais dirigido para a elevação do espírito à contemplação das regiões serenas acima das estrelas. Seduzido pelo prazer sensual, o poeta constrói outro lugar, acolhedor, tropical e paradisíaco, em que a promessa do prazer se realizaria sem o costumeiro séquito de culpa e de remorso.

De um ponto de vista religioso, o procedimento é condenável, pois o que se tenta é a recuperação do estado de inocência, a eliminação do pecado original, a recuperação do paraíso terrestre ("o verde paraíso dos amores infantis", "o inocente paraíso, cheio de prazeres furtivos" ${ }^{36}$ - dirá o poeta em "Moesta et errabunda") pela via do comprazimento na carne.

Uma vez mais o movimento é, em si mesmo, ambíguo. Se, por um lado, é de fato comprazimento nos sentidos e, por isso, pecaminoso, por outro é uma forma de revestir o impulso sexual de uma abrangência sensual que o transcende e quase neutraliza. A ambiguidade do movimento de "Perfume exótico" se torna mais clara quando o lemos na ordem do livro de 57, pois ali ele sucede imediatamente "As joias" ${ }^{37}$, este sim expressão direta e erótica do desejo sexual - e, por isso, um dos poemas censurados.

O que parece bastante fortalecido pela ordenação dos textos nas Flores do Mal é esse duplo movimento que podemos perceber na utilização do motivo do deslocamento (temporal ou espacial), em que a construção imaginária de um mundo favorável ao desfrute do sensual, do erótico, corresponde a um movimento de recusa momentânea, ou afetação de recusa, da pura sexualidade.

35 Parfum éxotique

36 V. 25 : "mais le vert paradis des amours enfantines"; v. 30 : "l'innocent paradis plein de plaisirs furtifs"

37 Les bijoux 
Esse movimento duplo é perceptível também no poema mais famoso dedicado ao tema do deslocamento, “O convite à viagem”, que ganha quando lido em relação com o que o precede e o que o segue imediatamente. O que o precede é "A bela nau" ${ }_{38}$. O que vem após ele é "O irreparável”. Em "A bela nau" temos uma mulher sedutora, comparada a um navio que deixa o porto "seguindo um ritmo doce, e preguiçoso, e lento". Toda ela é um símile da viagem e em partes de seu corpo se representam, inclusive, alguns dos perigos míticos da navegação - as pernas são feiticeiras que preparam negro filtro em um vaso profundo; os braços, grandes cobras das regiões tropicais. "O convite à viagem” é, assim, simultaneamente o convite ao embarque na "bela nau" e uma reação à carnalidade chocante daquele poema.

A construção mental e o convite à conquista do espaço adequado à vivência da plenitude sensual têm aqui também dupla função: por um lado, é um discurso sedutor dirigido a uma mulher; por outro lado, é um efetivo adiamento da vivência concreta da sexualidade.

Là-bas é, assim, também e sempre outro momento, e não só porque seria preciso ir até lá para que se pudesse viver plenamente a sexualidade, mas porque esse là-bas não é lugar algum, é mera intenção de não ser aqui, vaga possibilidade e sonho.

Da mesma forma, o jadis das Flores não tem realidade histórica. Esfinges, tigres, montanhas de cristal, suas caravanas, oásis e tamarineiros são basicamente índices de outro lugar e de outro tempo e valem sempre como oposições ao presente parisiense, que é a única e determinante realidade dos poemas.

É isso que mostra "O irreparável" ${ }^{39}$, poema que se segue a "O convite à viagem", e localizado exatamente no meio das Flores do Mal (poema L): que é impossível transcender espacial ou temporalmente os limites do universo dos valores cristãos, em que o gozo dos sentidos acarreta culpa e perdição. Não é possível iludir o "velho Remorso". Contra ele não há filtros elaborados por feiticeiras, nem possibilidade de transpor os limites físicos da nossa própria situação histórica. Por isso, a estrofe mais dolorosa do poema é a que nega a

38 Le beau navire 
transformação, pelo desejo e pela interpretação das correspondências, da paisagem hibernal europeia em clara cena tropical.

Temos aí um amargo contraponto ao gracioso quadro dos "Ciganos em viagem". Se lá uma divindade pagã se encarregava de proteger e alimentar os viajantes, aqui é o Diabo que preside à lúgubre cena noturna.

Depois de "O irreparável" [L], o sonho exotista das Flores do Mal praticamente termina enquanto possibilidade ou esperança de transcendência. As paisagens idealizadas que se associavam à sublimação e ao encanto amoroso reduzem-se agora a uma simples "Conversa" [LI] ${ }^{40}$ Ou se transfiguram no horror de "Uma viagem a Citera". ${ }^{41}$

III

Retornemos agora a "Moesta et errabunda" [LXII] e sua posição no livro. Neste último poema de tema exotista, estrategicamente colocado - como vimos - antes da série dos spleens, se dá a recolha da temática. Fica aí patente que o desejado movimento no espaço é apenas sucedâneo do único movimento desejado, mas impossível, o movimento no tempo, em direção a um passado em que não existia nem o crime, nem a dor; consequentemente, um passado sem culpa e sem remorso.

Esse tempo anterior, como vimos, comparece aqui com o seu próprio nome: “o verde paraíso dos amores infantis".

Mas não há caminho de volta, no tempo como na consciência, e a distância espacial é a mesma distância temporal, pois o almejado paraíso está "mais longe do que a Índia e que a China". E, já agora, anunciando o spleen e a revolta, fica claro que, se por meio da decifração das correspondências, parecia possível recompor a unidade perdida do mundo, esse tempo quase isento de culpa é irrecuperável. A busca das correspondências - a desesperada tentativa de atribuir dignidade à fruição e livre exercício dos sentidos - fracassa

40 Causerie

41 Un voyage à Cythère 
como projeto de abolição da culpa e do remorso. Os poemas de número LVIII a LXIII ${ }^{42}$ tratam do spleen, o estado de desagregação moral que decorre desse fracasso.

E aqui deparamos o último desenvolvimento da temática exotista, já não como possibilidade de fuga e transcendência, mas, por assim dizer, em negativo, como fixidez e morte. O poema LX, que começa "Eu tenho mais recordações do que há em mil anos", com a sua esfinge fixada no fundo do deserto, ecoa o que começa "Amo a recordação daqueles tempos nus", assim como o LXI, "Spleen", ecoa "A vida anterior", e as "Brumas e chuvas" [LXIII] (título do soneto depois deslocado para os "Quadros Parisienses") se contrapõem aos céus amplos e abertos dos convites à viagem.

Com o triunfo do spleen, afirma-se a situação irremediável: o confinamento ao presente e ao ambiente da cidade, isto é, à decadência. Por isso, encerrando a glosa do exotismo, o poema LXIV, "O irremediável" ${ }^{43}$, põe em cena sucessivos símbolos do fracasso da viagem exploratória impossível e interrompida - a confirmação da queda, enfim: e eis o poeta refletido nesse "anjo, imprudente viajante" que se debate no fundo de um pesadelo, nesse condenado descendo às escuras um abismo cheio de répteis, e, por fim, na bela nau, agora aprisionada no gelo polar.

\section{REFERENCIAS}

BAUDELAIRE, C. Les fleurs du mal. Édition établie selon un ordre nouveau, présentée et annotée par Yves Florenne. Paris: Le Livre de Poche, 1974. 1995.

Poesia e prosa. Edição organizada por Ivo Barroso. Rio de Janeiro: Nova Aguilar, Les fleurs du mal par M. Charles Baudelaire. In: BAUDELAIRE, C.

Oeuvres complètes. Texte établi, présenté et annoté par Claude Pichois. Paris: Gallimard, 1975.

Artigo recebido em 29/07/2012

Aceito para publicação em 24/09/2012

42 La cloche fêlée, Spleen (Pluviose irrité), Spleen (J'ai plus de souvenirs), Spleen (Je suis como le roi), Spleen (Quand le ciel bas et lourd), Brumes et pluies.

43 L'irremédiable 